\section{SCIENTIFIC PAPERS}

STOCKHOLM, SWEDEN

20-23 JUNE 1993

\title{
8th World Congress on Emergency and Disaster Medicine (WCEDM)
}

\section{AIR TRANSPORTATION ACCIDENTS}

The abstracts that follow are inclusive of the Scientific Papers presented at the 8th World Congress for Emergency and Disaster Medicine conducted in Stockholm, Sweden from 20 through 23 June 1993. They are grouped according to primary topic as they were presented at the Congress. The scope of these papers is very board and is indicative of the breadth of the field of Prehospital, Disaster, and Emergency Medicine. It is anticipated that the better papers presented at this Congress will be submitted for publication in Prehospital and Disaster Medicine in the near future. Completed manuscripts should be submitted to the editorial office.

Publication of these abstracts is supported in part by PhysioControl and is evidence of the ongoing commitment of this organization to the practice of Prehospital, Emergency, and Disaster Medicine. As editor, I express the appreciation of the World Association for Disaster and Emergency Medicine (WADEM) and the Organizing and Scientific Committees of the Swedish Society for Disaster Medicine for the support. Physio-Control also provided resources for the publication of the venue and abstract book for the Congress.

Further, I am most grateful to the energies and cooperation of the host Society in the acquisition, peer-review, and preparation of these abstracts. In particular, I am indebted to Dr. Per Kulling, whose tireless efforts and wonderful organizational skills made publication of the remarkable volume of this material possible. These abstracts constitute a significant contribution to the literature in this new and exciting field of medicine.

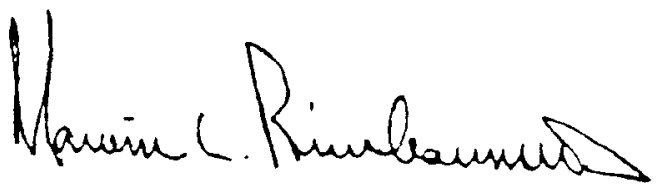

Marvin L. Birnbaum, MD, $\mathrm{PhD}$

Editor-in-Chief
1

\section{Plane Crash: Roissy-Charles-De-Gaulle Airport}

Leclercq G, Prudhomme C, Fleury $M$, Cupa $M$

SAMU 93, Hospital Avicenne

Bobigny Cedex, France

On 6 January 1993, Lufthansa, a Dashmitt airplane, crashed on the runway at the Roissy airport. An accident of this nature never had occurred at this airport prior to this incident.

The experience of the Seine-Saint-Denis SAMUs, which implemented the aid plan established for this type of disaster, is described.

The final total included four deaths, five seriously injured, and 11 slightly injured. All victims were treated in a triage center established by the airport's medical service. The victims were transferred to hospitals, in accordance with specific regulations established by the SAMU.

\section{2}

\section{The Faro Aircraft Crash}

Hustinx $P A$, * Kramer $M^{* *}$

* Department of Traumatology, University Hospital of the Free University Amsterdam, The Netherlands

** Department of Haematology, University Hospital-Leiden Leiden, The Netherlands

Objective: To describe repatriation, within a 50-hour time period, of 265 Dutch survivors, 80 of whom were minor to major casualties, after an aircraft crash in Portugal. An organizational blueprint will be presented relative to repatriation of a large number of tourists after a disaster abroad.

Methods: An eyewitness account will be given by one of the physicians involved in the repatriation process. Recommendations concerning the organization of such an effort, abroad and at home, will be provided.

Conclusion: Fast repatriation of wounded tourists from abroad to their own country is possible and should be done for both medical and psychological reasons. 